\title{
The Effect of Phenformin-HCl on Patients with Diabetes Mellitus, Studied under Strict Balance Conditions
}

\author{
C. A. Geldermans, J. Terpstra and H. M. J. Krans \\ Diabetes Unit of the Dept. for Diseases of Metabolism and Endocrinology, University Hospital, Leiden, The Netherlands
}

Received: February 19, 1975, and in revised form: July 11, 1975

\begin{abstract}
Summary. Under strict balance conditions we studied the effect of phenformin in 5 patients with diabetes mellitus. In all cases phenformin lowered the blood glucose values, and all patients showed a reduction of glycosuria. Contrary to other reports body weight increased during phenformin treatment. This was accompanied by positive nitrogen, phosphorus and calcium balances. The weight gain can be explained by the positive caloric balance, mainly caused by the diminished glycosuria. No change in B.M.R. or R.Q. was seen. During phenformin treatment there was a drop in cholesterol and total lipid levels in 4 patients. No conclusions could be drawn about the effect of phenformin on triglycerides,
\end{abstract}

phospholipids and lipoprotein spectra. Phenformin treatment did not affect the disappearance of glucose, nor the insulin levels after intravenous glucose loading. During oral glucose loading phenformin caused a significant fall in blood glucose levels, accompanied by an increased insulin response in one patient. In the other 4 patients phenformin had no effect on either parameter.

Key words: Phenformin, biguanides, weight reduction, caloric balance, balance study, lipid spectra, glucose tolerance, insulin levels.
Biguanides are used mainly to treat the elderly obese diabetic. According to many investigators biguanides reduce the elevated blood glucose level $[7,8$, $11,13,17,21,37]$, body weight $[1,4,11,17,18,34$, $37,42]$ and glucose excretion in urine [11]. A concomitant reduction of elevated cholesterol [1], triglyceride and insulin levels [24, 28, 34] has been reported.

Since reduction of glycosuria without diminishing the diet should cause an increase in the available energy in the body, the weight loss is difficult to un- derstand. By investigating patients under strict balance conditions, we hoped to learn more about the mechanism by which biguanides reduce both the blood sugar level and the body weight.

\section{Materials and Methods}

We studied 5 otherwise healthy diabetics from our out-patient department (Table 1). They were hospitalized in the metabolic ward during the whole study.

Table 1.

\begin{tabular}{|c|c|c|c|c|c|c|c|c|c|}
\hline patient & duration & treatment & height(m) & weight $(\mathrm{kg})^{\mathrm{a}}$ & $\begin{array}{l}\text { composition } \\
\operatorname{diets}(g)^{\mathrm{b}}\end{array}$ & of the & & $\begin{array}{l}\text { caloric val } \\
\text { the diets }\end{array}$ & $\begin{array}{l}\text { ue of } \\
\text { kcal.) }\end{array}$ \\
\hline date of birth & diab. (years) & before study & & & carbohydr. & protein & fat & bombcal. & table ${ }^{b}$ \\
\hline $\begin{array}{l}\text { 1. } \underset{\text { f A. K.-v. R. }}{03-01-22} \\
\text {. }\end{array}$ & 7 & $\begin{array}{l}\text { diet } \\
+ \text { tolbutamide }\end{array}$ & 1.55 & 51.9 & 216 & 82 & 72 & 2246 & 1843 \\
\hline $\begin{array}{l}\text { 2. } \underset{1}{+} \mathrm{HC} . \mathrm{v} . \mathrm{V} . \mathrm{-V} . \\
18-01-17\end{array}$ & 3 & diet & 1.65 & 72.5 & 243 & 85 & 83 & 2413 & 2096 \\
\hline $\begin{array}{l}\text { 3. O H. v. V. } \\
06-09-00\end{array}$ & 10 & diet & 1.76 & 75.8 & 274 & 101 & 89 & 2493 & 2312 \\
\hline $\begin{array}{l}\text { 4. } \text { O }^{7} \mathrm{~W} . \mathrm{B} . \\
22-11-22\end{array}$ & $<1$ & diet & 1.67 & 84.0 & 287 & 143 & 134 & 3410 & 2925 \\
\hline $\begin{array}{l}\text { 5. O' JJ. v. V. } \\
04-12-05\end{array}$ & $<1$ & diet & 1.75 & 76.0 & 209 & 116 & 109 & 2846 & 2529 \\
\hline
\end{tabular}

\footnotetext{
a At the beginning of the first A period.

'Calculated from the official table of the "Nederlandse Voedingsraad".
} 

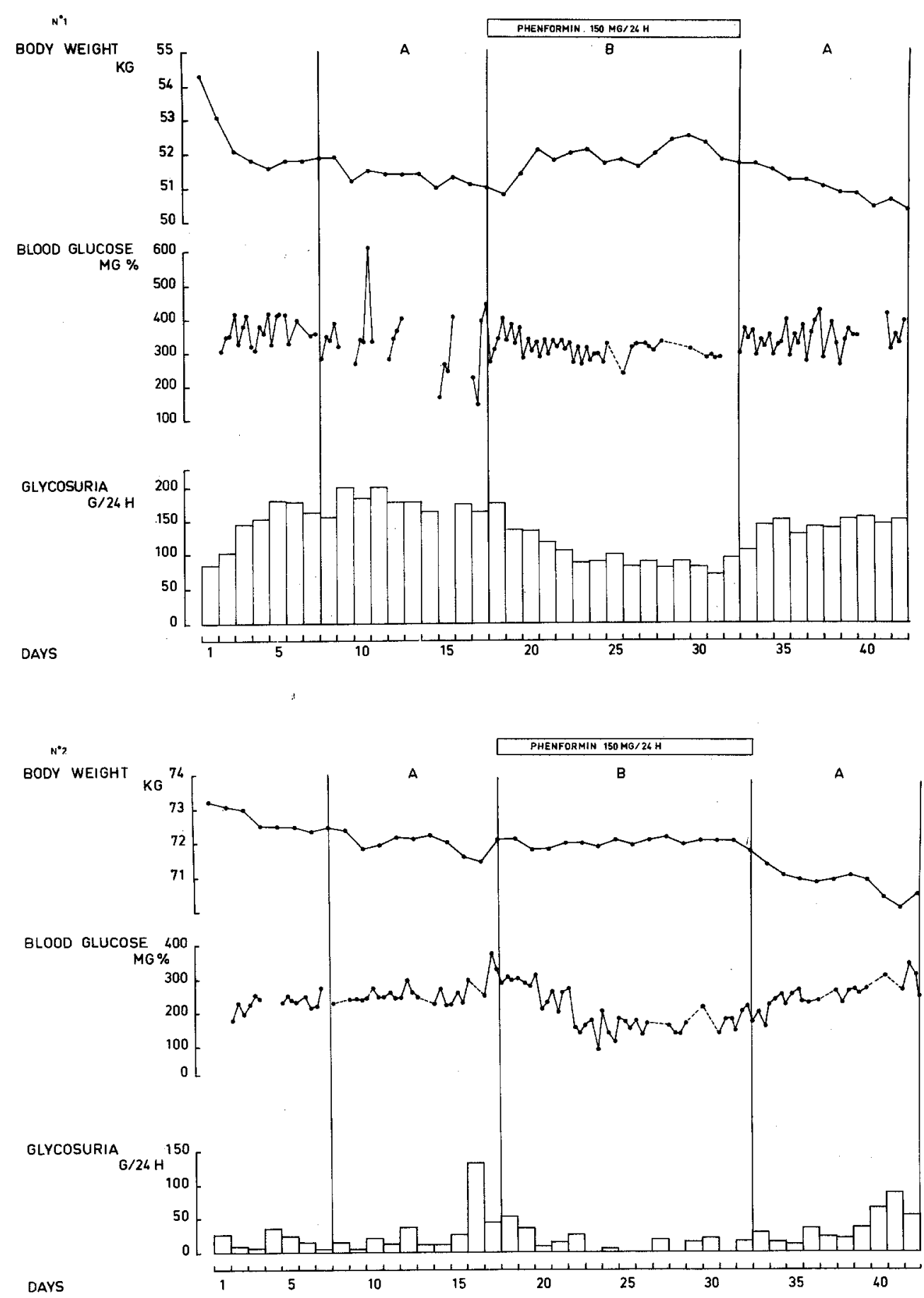

To exclude gastrointestinal side-effects phenformin capsules $(3 \times 50 \mathrm{mg})$ were prescribed before the final selection of the patients, but gastrointestinal disturbances forced us to omit one patient from the study. Two weeks before admission oral hypoglycemic therapy was withdrawn.

The diet was individually adjusted such that the body weight would remain constant during the non-phenformin periods. At identical times 3 isocaloric meals and 3 isocaloric snacks were given. The meals for each balance study were all prepared and divided at one time before the start of the study and kept frozen until consumption. No other food or drinks than those included in the diet were allowed except a measured amount of distilled water. The patients were required to consume all meals com- 

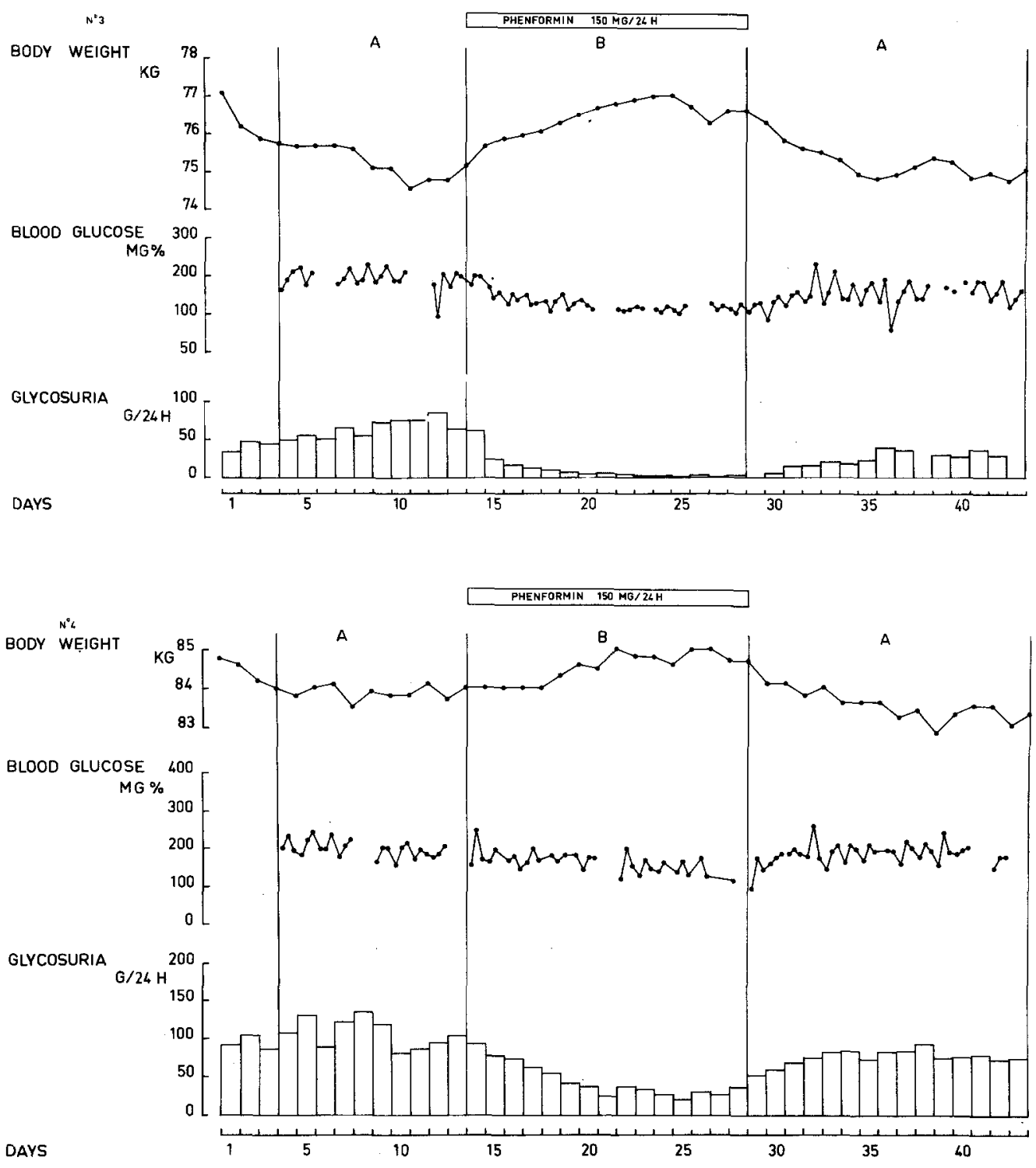

N5

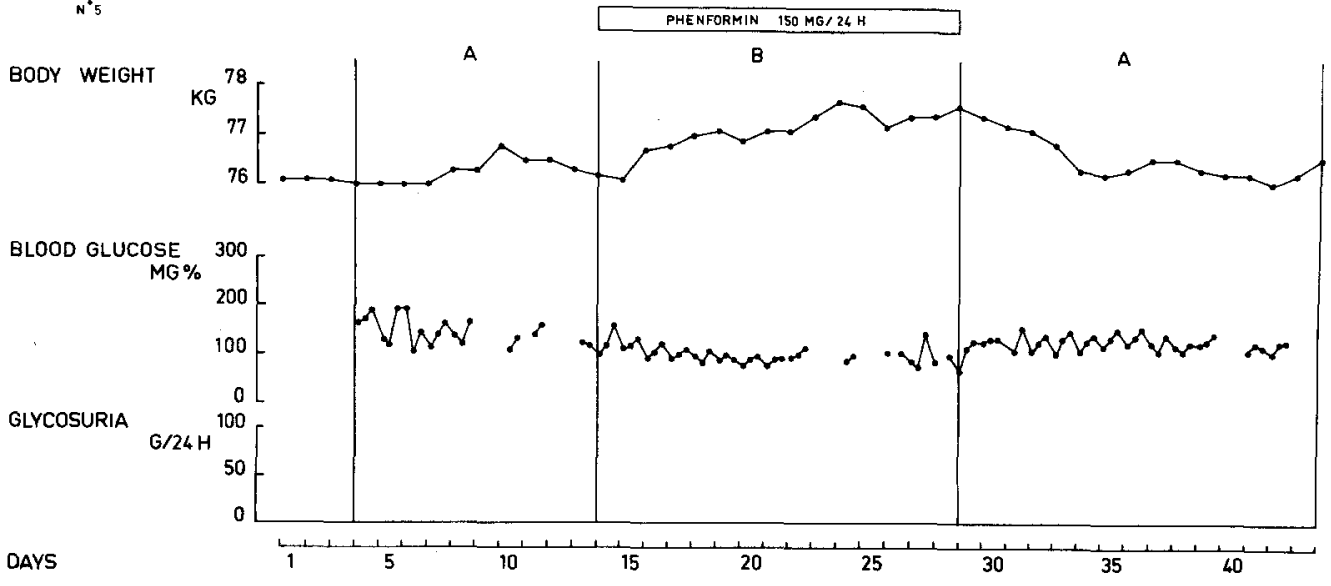

Fig. 1. Data on body weight, glucose levels and glycosuria in pat. 1-5 
pletely. We tried to keep the activities of the patients identical to that at home.

After a period of 7 days, in which the patient became accustomed to the diet and slight modifications could be made, the study was carried out according to the A-B-A system. During the A periods (10-15 days) the patients received a placebo capsule 3 times a day and in the $B$ period (15 days), a capsule of $50 \mathrm{mg}$ phenformin 3 times a day. Body weight (at 8.30 a.m.), blood glucose values (at 8 a.m., 1 p.m., 5 p.m., using the glucose oxidase method [41] and $24 \mathrm{hrs}$ sugar (polarimeter) and creatinine excretion in the urine were determined daily. Faeces were collected over 5-day periods, marked by carmine red. Chromium oxide $\left(\mathrm{Cr}_{2} \mathrm{O}_{3}\right.$, capsules of $\left.500 \mathrm{mg}\right)$ was given 3 times a day to quantify the faecal collection [40]. Faeces, urine and three thoroughly mixed daily diets were analyzed chemically and in the bomb calorimeter according to Miller and Payne [33]. Calcium was estimated by complexon III ( $\mathrm{Na}_{2}$ EDTA) titration, using murexide as an indicator, phosphorus according to a modification of Fiske and Subbarow [20], and nitrogen according to Kjehldahl [23].

At the end of every period the cortisol levels during that day were determined ( 8 a.m., 5 p.m., 12 p.m.) [31], as well as total lipid, cholesterol and triglyceride levels and lipoprotein spectra in fasting blood samples [38]. At the start and the end of each period serum osmolarity, urea, total protein, hemoglobin and hematocrit were determined as a measure of the hydration of the patient.

An oral and an intravenous glucose tolerance test on subsequent days were performed at the end of each period, and blood sugar (Nelson-Somogyi [35]) and plasma insulin levels (Yalow and Berson [44]) were determined. All blood samples were collected in heparin via an indwelling needle. An hour before testing, one placebo or phenformin capsule $(50 \mathrm{mg})$ was given. On these days the entire daily diet was consumed but the times of consumption were changed. For the intravenous glucose tolerance test 25 grams of glucose were injected in $4 \mathrm{~min}$. Samples were drawn at zero (in the middle of the injection), 2, 4, 6, 9, 12, 20, 30, 45 and $60 \mathrm{~min}$. The rate constant for the fractional disappearance of the injected glucose (K-value) was calculated from the least square regression line. For the oral glucose tolerance test 50 grams of glucose were given. Blood was sampled in the fasting state and 30,60 , 90,120 and 150 min after glucose administration.

\section{Results}

Fig. 1 shows the effect of phenformin (B period) on body weight, blood glucose and glycosuria in patients
1-5. During the phenformin period a decrease and stabilization in blood glucose levels, with an accompanying reduction in glycosuria, occured in all patients within a few days. When phenformin was withheld, the return to pre-phenformin levels also took several days. In Fig. 2 and Table 2 we see that during phenformin therapy there is an absolute or relative (patient 2) increase in body weight accompanied by an absolute or relative (patient 2) positive $\mathrm{N}, \mathrm{Ca}$ and $\mathrm{P}$ balance.

The calculated caloric balance (Table 3 ) shows that phenformin induces a positive balance. This is most marked in the patients with a substantial decrease in glycosuria. The caloric value of the faeces is practically unchanged during phenformin therapy, indicating the absence of malabsorption. Table 4 indicates that it is not likely that metabolites of high caloric value are excreted during phenformin substitution.

In 4 patients (1, 3, 4 and 5) no effect of phenformin on blood sugar or insulin levels after oral glucose loading is seen (Fig. 3). The insulin levels in these patients were already low before phenformin treatment. The only patient (2) with an increased insulin response during phenformin and a concomitant reduction of the blood sugar levels showed higher insulin levels before phenformin than the other patients.

The intravenous glucose loading tests revealed that none of the patients showed a significant change in $\mathrm{K}$ values during phenformin treatment (Table 5).

In patients $1,2,3$ and 4 , but not patient 5 , there was a decrease in cholesterol and total lipid levels during phenformin treatment (Table 6). The phospholipids, triglycerides and free fatty acids exhibited variable changes during phenformin therapy. The only change seen in the lipoprotein spectra is a decrease in the $\beta$-lipoproteins during phenformin treatment.

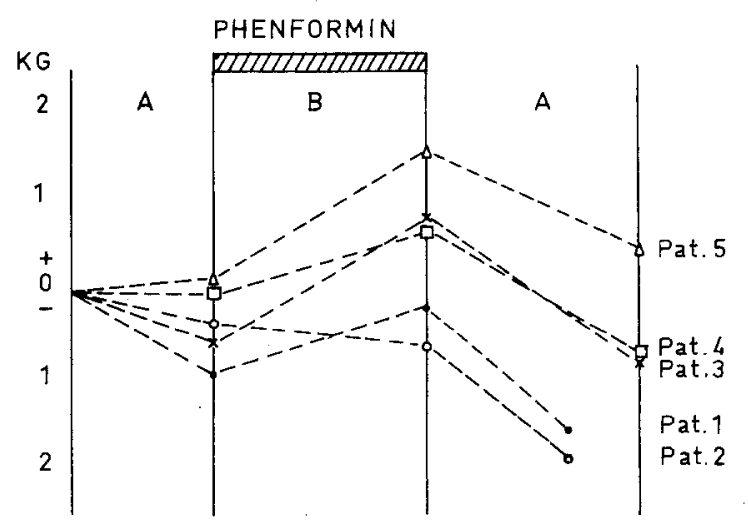

Fig. 2. Weight changes during both control (A) periods and the phenformin (B) period, related to the body weight at the beginning of the first A period (zero) 
Table 2. Nitrogen, calcium and phosphor balances in the three periods ( $A, B$ and $A$ )

\begin{tabular}{ccccccccccc}
\hline & \multicolumn{3}{c}{ N-balance g/24h } & \multicolumn{4}{c}{ Ca-balance $\mathrm{mg} / 24 \mathrm{~h}$} & \multicolumn{3}{c}{ P-balance mg/24h } \\
\hline Pat. & A & B & A & A & B & A & A & B & A \\
\hline 1 & -2.0 & -1.3 & -2.1 & -56 & -41 & -64 & -174 & -60 & -163 \\
2 & +0.4 & +1.3 & +0.9 & -106 & -6 & -174 & -109 & +73 & -174 \\
3 & +0.7 & +1.5 & +0.5 & +133 & +202 & +160 & +35 & +141 & +37 \\
4 & -1.4 & -0.0 & $-1,0$ & +94 & +108 & +158 & -26 & +166 & +23 \\
5 & +1.4 & +1.7 & -1.0 & +106 & +130 & +87 & -72 & +106 & -118 \\
\hline
\end{tabular}

Table 3. Caloric balance Kcal./24 h. (bombcalorimetre)

\begin{tabular}{|c|c|c|c|c|c|c|c|c|c|c|c|c|c|c|c|}
\hline & \multicolumn{3}{|c|}{ Pat. 1} & \multicolumn{3}{|c|}{ Pat. 2} & \multicolumn{3}{|c|}{ Pat. 3} & \multicolumn{3}{|c|}{ Pat. 4} & \multicolumn{3}{|c|}{ Pat. 5} \\
\hline & A & B & A & A & B & A & A & B & A & A & B & A & A & B & $\mathrm{A}$ \\
\hline $\begin{array}{l}\text { Intake } \\
\text { (diet) }\end{array}$ & 2246 & 2246 & 2246 & 2413 & 2413 & 2413 & 2493 & 2493 & 2493 & 3410 & 3410 & 3410 & 2846 & 2846 & 2846 \\
\hline \multicolumn{16}{|l|}{ Output } \\
\hline feces & 157 & 144 & 166 & 118 & 127 & 112 & 113 & 143 & 139 & 137 & 157 & 141 & 144 & 111 & 129 \\
\hline urine & 818 & 550 & 685 & 203 & $\mathrm{a}$ & 244 & 368 & 137 & 233 & 753 & 397 & 596 & 144 & 131 & 150 \\
\hline total & 975 & 694 & 851 & 321 & & 356 & 481 & 280 & 372 & 890 & 554 & 737 & 288 & 242 & 279 \\
\hline Balance & 1271 & 1552 & 1395 & 2092 & & 2057 & 2012 & 2213 & 2121 & 2520 & 2856 & 2673 & 2558 & 2604 & 2567 \\
\hline
\end{tabular}

a For technical reasons the bombcalorimetric estimation of the urine (B period) in pat. nr 2 failed.

Table 4. Caloric value of the urine after subtraction of the caloric value of the glucose (Kcal./24 h)

\begin{tabular}{|c|c|c|c|c|c|c|c|c|c|c|c|c|c|c|c|}
\hline & \multicolumn{3}{|c|}{ Pat. 1} & \multicolumn{3}{|c|}{ Pat. 2} & \multicolumn{3}{|c|}{ Pat. 3} & \multicolumn{3}{|c|}{ Pat. 4} & \multicolumn{3}{|c|}{ Pat. 5} \\
\hline & A & & A & A & B & A & $\mathrm{A}$ & B & A & A & B & A & A & B & A \\
\hline $\begin{array}{l}\text { total cal. val. urine } \\
\text { (bombcalorimetre) }\end{array}$ & 818 & 550 & 685 & 203 & & 244 & 368 & 137 & 233 & 735 & 397 & 596 & 144 & 131 & 150 \\
\hline $\begin{array}{l}\text { cal. val. glucose } \\
(\mathrm{g} \text {. glucose } \times 4.23 \mathrm{kcal})\end{array}$ & 739 & 434 & 597 & 135 & 58 & 158 & 244 & 32 & 76 & 524 & 219 & 346 & - & - & - \\
\hline Balance & 79 & 116 & 88 & 68 & & 86 & 144 & 105 & 157 & 211 & 178 & 250 & 144 & 131 & 150 \\
\hline
\end{tabular}

Table 5. Glucose assimilation coefficient ( $K$-value) in the intravenous glucose tolerance tests

\begin{tabular}{lccc}
\multicolumn{4}{c}{ travenous glucose tolerance tests } \\
\hline Pat. & A & B & A \\
\hline 1 & 0.32 & 0.23 & 0.23 \\
2 & 0.25 & 0.43 & 0.34 \\
3 & 0.71 & 0.76 & 0.72 \\
4 & 0.66 & 0.41 & 0.46 \\
5 & 0.71 & 0.75 & 0.67 \\
\hline
\end{tabular}

Table 6. Total lipids $(\mathrm{mg} / 100 \mathrm{ml})$ and cholesterol $(\mathrm{mg} / 100 \mathrm{ml})$

\begin{tabular}{llrrl}
\hline Pat. & & A & B & A \\
\hline 1 & total lipids & 1071 & 1006 & 968 \\
& cholesterol & 323 & 273 & 300 \\
2 & total lipids & 732 & 701 & 744 \\
& cholesterol & 210 & 181 & 227 \\
3 & total lipids & 897 & 767 & 905 \\
& cholesterol & 290 & 244 & 288 \\
4 & total lipids & 1011 & 828 & 905 \\
& cholesterol & 300 & 245 & 269 \\
5 & total lipids & 841 & 844 & 898 \\
& cholesterol & 279 & 300 & 316 \\
\hline
\end{tabular}




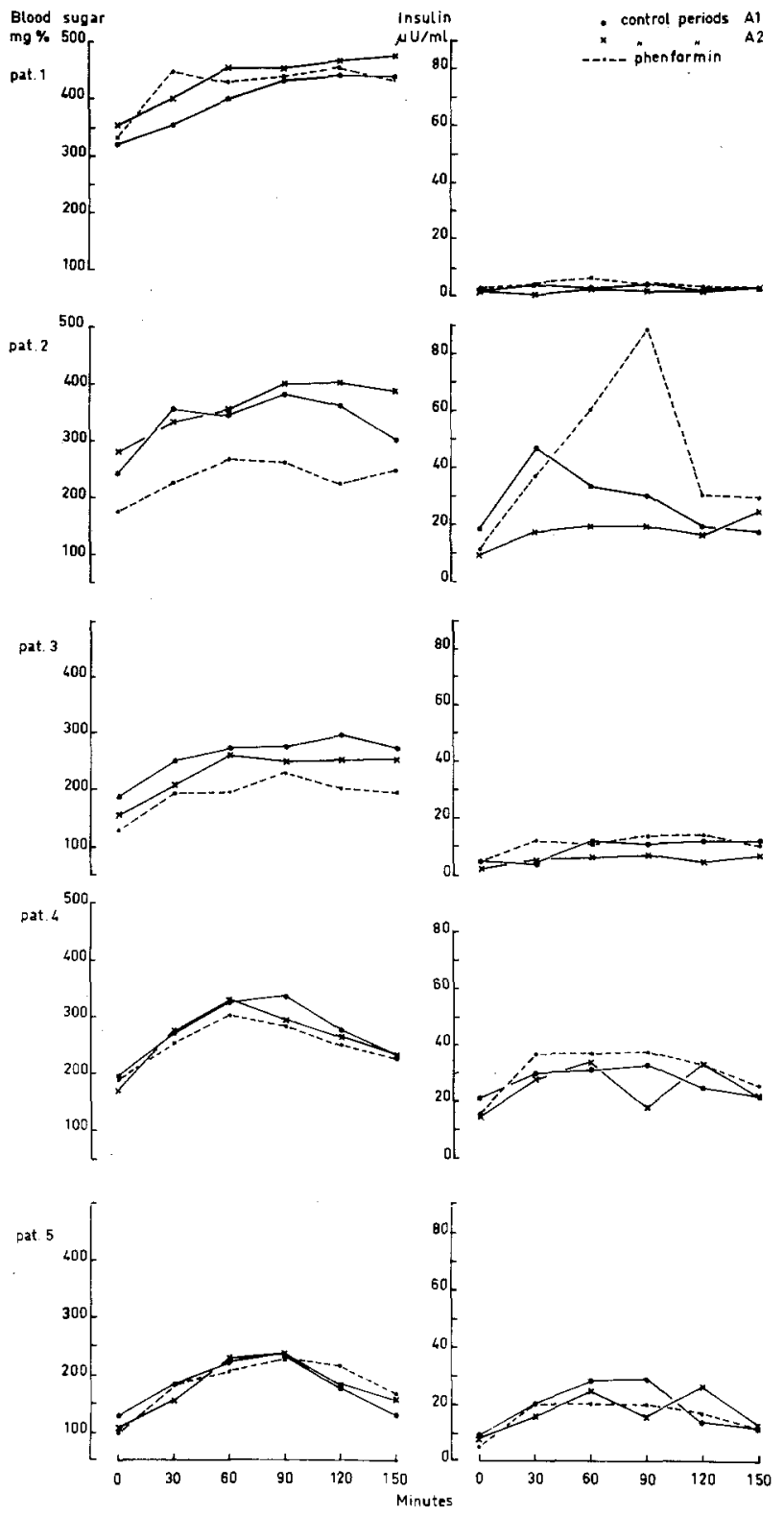

Fig. 3. Plasma insulin and blood sugar levels during the oral glucose tolerance test in pat. 1-5

\section{Discussion}

In contrast to other published data, all 5 of our patients gained weight during phenformin treatment with respect to the control periods. Many investigators report that biguanides induce a weight loss in obese patients with diabetes mellitus $[1,4,11,17,18,34,37$, 42]. This is attributed to anorexia [37], intestinal malabsorption [42, 43], suppression of high insulin levels resulting in a reduction of lipogenesis $[18,34]$ or stimulation of thermogenesis $[26,27]$. In none of these studies were the patients observed under strict balance conditions. Thus the loss of weight might be the result of a reduced caloric intake due to the anorexic effect of the biguanides or a closer adherence to the prescribed diet because of the more elaborate control. Apart from the direct interactions of energy uptake and release, weight reduction may also be caused by a shift in body composition from protein to fat. Protein calories are approximately 10 times heavier than fat calories, due to the adhering water mantle and the lower energetic value of protein. We thought it necessary therefore to observe our patients under strict balance conditions to exclude the effect of changes in food intake.

In 4 patients $(1,3,4$ and probably 2$)$ there was a positive caloric balance in the phenformin period. The caloric gain can be explained by the reduced glycosuria. The increased retention of $\mathrm{N}, \mathrm{Ca}$ and $\mathrm{P}$ during the phenformin period, compared to the control periods, also indicates that there is an increase in body tissue. For patient 5, the lack of glycosuria and the approximate equilibrium of the caloric balance under phenformin ( $+40 \mathrm{kcal} . / 24 \mathrm{hrs})$ make it more difficult to explain the weight changes. Decreased physical activity during phenformin treatment can be excluded in this patient. An increase in body tissue is not likely, as there was almost no caloric gain. The nitrogen balance does not support an important shift of fat to protein. The weight gain might be explained by fluid retention. However we could not estimate the fluid balance with sufficient accuracy, since we had no facilities to measure total body water. Attempts to calculate fluid balances from the total intake and the urinary excretion of water gave too variable results to be of any use.

Direct determinations of the caloric content of feces and urine are not reported in the literature, except by Stowers [43], who found during clinical observation of one overweight patient with diabetes mellitus treated with $225 \mathrm{mg}$ phenformin per day, that the caloric value of the feces increased by $28 \%$. We found that such high doses of phenformin can induce gastro intestinal disturbances, e.g. diarrhea. The results of the bomb calorimetric estimations indicate that in our patients there is probably no loss of substrates with a high caloric value in faeces or urine.

The theory that the weight loss during phenformin therapy is due to an increased metabolic rate is not supported by the findings of Stowers et al. [42] since neither B.M.R. nor R.Q. changed significantly from the values measured during the control periods. We also found no changes in B.M.R. or R.Q. (not shown here). Moreover the positive nitrogen balance during phenformin excludes increased catabolism. 
To eliminate anorexia as a possible cause of weight loss during phenformin treatment, food intake during our study was constant. Nevertheless most patients felt more discomfort during the phenformin period as a result of the consumption of their entire diet. In one patient (not included in this report) anorexia was so strong that vomiting developed and we had to discontinue the study. We feel that if our patients had not been required to consume their whole diet, they would definitely have reduced their food intake.

Theoretically phenformin may lower the blood glucose level by reducing intestinal resorption $[9,10$, $13,14,25]$, enhancing peripheral glucose utilization $[7,8,19,22]$ or reducing endogenous glucose production $[2,5,32]$. A reduced intestinal glucose resorption is not supported by the bomb calorimetric data which show no increase in the caloric content of faeces and urine during phenformin treatment. This is in agreement with Olsen [36], who could not demonstrate carbohydrate malabsorption during phenformin treatment. Also the blood glucose values after oral glucose loading during phenformin administration are virtually unchanged in 4 out of 5 patients in comparison with the control periods. In the only patient who showed a significant decrease in glucose levels during phenformin treatment, the insulin values were also significantly higher. This does not support the malabsorption theory.

Another often stated assumption is that biguanides stimulate peripheral glucose utilization $[7,8,19,21$, 22]. The mechanisms which might be involved are not clear. Biguanides uncouple the oxidative phosphorylation in mitochondria [15]. A stimulating effect of biguanides on glucose transport has never been demonstrated. Phenformin does not stimulate the transport of glucose in isolated fat cells and it inhibits the stimulation of glucose uptake induced by insulin in such cells [29].

A more reasonable explanation, which is also supported by experiments in animals [2,12], might be a decrease in internal glucose production, although we could not prove this from our data.

After an oral glucose load phenformin is said to reduce the rise in blood glucose and insulin levels $[3,6$, $14,24]$. Only patient 2 showed a drop in blood glucose concentration, but with a concomitant rise in insulin levels. In the remaining 4 patients $(1,3,4$ and 5) phenformin did not have any effect (Fig. 3). This may be due to the fact that these patients were no longer able to secrete much insulin. Moreover, our patients received their regular dose of one capsule of phenformin $(50 \mathrm{mg})$ one hour before the test, in contrast to the total daily dose of $100-150 \mathrm{mg}$ administered by other investigators. The lack of effect may also be explained by the fact that in our study the patients had received phenformin for only ten days prior to the glucose tolerance tests. Boshell [6] observed no reduction of insulin levels in 4 patients ("hypersecretors") after oral glucose loading when they had taken phenformin for only one week $(100$ $\mathrm{mg} /$ day), but there was a significant decrease after 3 weeks of treatment. However in our patients the hypoglycemic effect of phenformin was already fully established after a few days. Since no effect of phenformin could be seen on the intravenous glucose tolerance test, this might indicate an action of phenformin in the gut (mucosa), possibly by stimulation of a hormonal factor(s) which enhances insulin secretion. In this connection it is interesting to note Loubatière's [30] report that phenformin stimulated insulin secretion in the $\operatorname{dog}$ (in vivo) and in the perfused rat pancreas.

There are many reports of a phenformin-induced drop in cholesterol and triglyceride levels in diabetic patients $[1,16,28,34,39]$. In 4 patients we found a decrease in both cholesterol and total lipid levels during phenformin treatment. No effect on phospholipids and triglycerides was seen. With regard to the lipoprotein spectra the only reproducible effect we observed was a reduction of the $\beta$-lipoprotein fraction, probably related to the decrease in cholesterol levels. Since most of our patients showed almost no insulin response to glucose loading, it does not seem likely that a decrease in insulin levels induces the reduction in cholesterol and total lipid levels. The caloric gain observed in our patients during phenformin treatment does not support the theory that a diminished supply of substrate for lipogenesis can explain the phenformin effect.

\section{Conclusion}

In patients with diabetes mellitus, observed under strict metabolic balance conditions, phenformin caused a decrease in blood glucose levels but no reduction of body weight. It also reduced the cholesterol and the total lipid content in the serum. The slight gain in weight during phenformin treatment can be explained by the diminished glycosuria in this period.

\footnotetext{
Acknowledgements. The technical assistance of Mrs. A. Cornelius - von Franquemont and the secretarial help of Miss M.G. A.T. Paal are gratefully acknowledged. We also thank Mr.W. Zuidervaart for the drawing of figures. The phenformin and placebo capsules used in this study were a gift of Winthrop B. V.
} 


\section{References}

1. Alterman, S. L., Lopez-Gomez, A. A.: Phenformin effect on body weight, lipids and glucose regulation. Ann. N. Y. Acad. Sci. 148, 884-891 (1968)

2. Altschuld, R. A., Kruger, F. A.: Inhibition of hepatic gluconeogenesis in guinea-pig by phenformin. Ann. N. Y. Acad. Sci. 148, 612-623 (1968)

3. Arky, R. A., Abramson, E. A.: Insulin response to glucose in the presence of oral hypoglycemics. Ann. N. Y. Acad. Sci. 148, 768-777 (1968)

4. Bloom, A.: Obesity and diabetes. Postgrad. Med. J. 47, June suppl. 430-434 (1971)

5. Boshell, B. R., Roddam, R. F., Mc Adams, G. L.: Effects of phenformin on insulin reserve and release. Ann. N. Y. Acad. Sci. 148, 756-767 (1968)

6. Boshell, B. R., Mc Adams, G. L., Chandalia, H. B., Roddam, R. F.: Phenformin and insulin secretion. Postgrad. Med. J. 45, May suppl., 38-46 (1969)

7. Butterfield, W. J. H., Whichelow, M. J., London, M. A.: The hypoglycaemic action of phenformin. Effect of phenformin on glucose metabolism in peripheral tissues. Diabetes 11, 281-286 (1962)

8. Butterfield, W. J. H., Whichelow, M. J.: Effect of diet, sulphonylureas, and phenformin on peripheral glucose uptake in diabetes and obesity. Lancet 1968 II, 785-788

9. Caspary, W. F., Creutzfeldt, W.: Analysis of the inhibitory effect of biguanides on glucose absorption. Inhibition of active sugar transport. Diabetologia 7, 379-385 (1971)

10. Caspary, W, F., Creutzfeldt, W.: Inhibition of intestinal amino acid transport by blood sugar lowering biguanides. Diabetologia 9, 6-12 (1973)

11. Clarke, B. F., Duncan, L. J. P.: Comparison of chlorpropamide and metformin treatment on weight and blood glucose response of uncontrolled obese diabetics. Lancet 1968 I, 123-126

12. Connon, J. J.: A differential action of phenformin in normal and diabetic, rat livers. Diabetologia 9, 47-49 (1973)

13. Czyzyk, A., Tawecki, J., Sadowski, J., Ponikowska, I., Szezepanik, Z.: Effect of biguanides on intestinal absorption of glucose. Diabetes 17, 492-498 (1968)

14. Czyzyk, A., Tawecki, J.: Untersuchungen über den Einfluß von Phenyläthylbiguanid auf den Verlauf von Belastungsproben mit Insulin, Tolbutamid und Glukose bei Diabetes Mellitus. Diabetologia 2, 62-68 (1966)

15. Davidoff, F.: Effects of guanidine derivatives on mitochondrial function. J. biol. Chem. 246, 4017-4027 (1971)

16. Dempsey, M. E.: Inhibition of lipid biosynthesis. Ann. N. Y. Acad. Sci. 148, 631-646 (1966)

17. Drury, M. J., Timoney, F. J.: Experience with phenformin as an oral antidiabetic agent. J. Irish med. Ass. 63, 391-394 (1970)

18. Faludi, G., Chayes, Z., Gerber, P.: Rational treatment of the obese diabetic. Postgrad. Med. 43, 92-96 (1968)

19. Felber, J. P., Gomez, F., Büber, V., Jéquier, E.: Effect of biguanides on the peripheral oxidation of glucose. Acta Endocr. 67, suppl. 155, 192 (1971)

20. Fiske, C. H., Subbarow, Y.: The colorimetric determination of phosphorus. J. biol. Chem. 66, 375-400 (1925)

21. Gomez, F., Felber, J. P.: Metabolic effects of butylbiguanide during long-lasting intravenous glucose infusion in normal human subjects. Horm. Metab. Res. 2, 72-75 (1970)

22. Gomez, F., Jéquier, E., Rüedi, B., Felber, J. P.: Peripheral action of butyl-biguanide in man: increased glucose uptake and glucose oxidation. Diabetologia 6, 628 (1970)

23. Gorter, E., de Graaff, W. C.: Klinische diagnostiek. 7e druk, pp. 434-437. Leiden: Stenfert Kroese 1956
24. Grodsky, G., Karam, J. H., Pavlatos, F. Ch., Forsham, P. H.: Reduction by phenformin of excessive insulin levels after glucose loading in obese and diabetic subjects. Metabolism 12, 278-286 (1963)

25. Hollobaugh, S. L., Bhaskar, M., Kruger, F. A.: Studies on the site and mechanism of action of phenformin on glucose metabolism in normal subjects. Diabetes 19, 45-49 (1970)

26. Irsigler, K.: Zum Energiehaushalt des menschlichen Organismus. Wien. klin. Wschr. 47, 845-854 (1969)

27. Irsigler, K., Schütz, P.: Energy utilisation in obese subjects changed by dimethylbiguanide. Diabetologia 6, 633 (1970)

28. Kissebah, A. H., Adams, P. W., Wynn, V.: Inter-relationship between insulin secretion and plasma free fatty acid and triglyceride transport kinetics in maturity onset diabetes and the effect of phenethyibiguanide (phenformin). Diabetologia 10, 119-130 (1974)

29. Krans, H. M. J., Arkesteijn, C., Terpstra, J.: The anti-insulin effect of phenformin (phenethylbiguanide) as demonstrated on isolated fat cells of the mouse. Diabetologia 6, 51 (1970)

30. Loubatières, A., Mariani, M. M., Jallet, F.: The mechanism of action of the biguanides. Role of the endocrine pancreas and of the extra pancreatic tissues. Diabetologia 8, 56 (1972)

31. Mattingly, D.: A simple fluorimetric method for the estimation of free 11-hydroxycorticoids in human plasma. J. Clin. Path. 15, 374-379 (1962)

32. Meyer, F., Ipaktchi, M., Clauser, H.: Specific inhibition of gluconeogenesis by biguanides. Nature 213, 203-204 (1967)

33. Miller, D. S., Payne, P. R.: A ballistic bomb calorimeter. Brit.J. Nutr. 13, 501-508 (1959)

34. Mirsky, S.: Influence of hypoglycemic therapy on blood lipids and body weight in diabetes mellitus. Ann. N. Y. Acad. Sci. 148, 937-944 (1968)

35. Nelson, N.: Photometric adaptation of Somogyi method for determination of glucose. J. biol. Chem. 153, 375-380 (1944)

36. Olsen, W. A., Rasmussen, H. K., Madison, B. S.: Effect of phenformin on carbohydrate absorption in man. Diabetes 23, 716-718 (1974)

37. Patel, D. P., Stowers, J. M.: Phenformin in weight reduction of obese diabetics. Lancet 1964 II, 282-284

38. Pries, C., van Gent, C. M., Baes, H., Polano, M. K., Hulsmans, H. A. M., Querido, A.: Primary hyperlipoproteinemia: The clinico-chemical classification of the most common types. Clin. chim. Acta 19, 181-190 (1968)

39. Schaefer, L. E.: Hyperlipidemia. Ann. N. Y. Acad. Sci. 148, 925-936 (1968)

40. Sluys Veer, J. van der: Een onderzoek over osteoporose bij het syndroom van Cushing met behulp van tetracycline en radioactief calcium. pp. 131-132. Leiden: Thesis 1968

41. Slik, W. v. d., Koevoet, A. L.: A modified automated enzymatic glucose determination. Clin. chim. Acta 27, 325-330 (1970)

42. Stowers, J. M., Bewsher, P. D.: Studies on the mechanism of weight reduction by phenformin. Postgrad. Med. J. 45, May suppl., 13-16 (1969)

43. Stowers, J. M.: Written communication. Editorial. JAMA 213, 1676-1677 (1970)

44. Yalow, R. S., Berson, S. A.: Immunoassay of endogenous plasma insulin in man. J. clin. Invest. 39, 1157-1175 (1960)

C. A. Geldermans, M. D.

Diabetes Unit of the Department for

Diseases of Metabolism and Endocrinology

University Hospital

Leiden 2405

The Netherlands 